\title{
Practical usability of CAT Model - a case study
}

\author{
Jaroslav Hradílek
}

Masarykova Univerzita, Brno, Faculty of Economics and Administration, Department of Corporate Economy, Lipová 507/41a, 60200 Brno, Czech Republic; 10955@mail.muni.cz

\begin{abstract}
The average life span of an organization, irrespective of its size, is $12 \frac{1}{2}$ years. The majority of companies which get into a crisis find themselves in this situation because of internal factors. To survive in the evolving and more and more demanding environment, organisations have to focus on their internal processes, leadership and management. However, there is no reliable and easily usable tool or model evaluating such criteria of an organisation in place. Following the need to have a lean, yet reliable tool to evaluate a level of Leadership, Management Maturity and Culture a new Performance Model has been created. The CAT Model (acronym stands for Complex Assessment Tool) can be used to evaluate and assess its strong and weak sides using structured interviews. The usage of the tool proved useful, giving owners/management valuable feedback and areas with potential for improvement. This article describes its practical usability in an assessment carried out on a Czech company.
\end{abstract}

\section{An introduction into CAT model}

Despite the fact that enormous effort has been deployed in the field of strategy management, the "Search of excellence" does not seem to be any closer to its objective than in 1982, when the book from Peters \& Waterman has been published. Thought significant development has taken place, the evolving environment, competition, society and technology still force organisations to constantly adapt or die. Ever since the eighties business writers have been claiming that the world was getting more dynamic, turbulent, unpredictable and competitive. As it turned out, in retrospect the 1990s were 'a piece of cake' compared to what is happening now in the world [1].

There are many reasons attributable for company success of failure and both business community and academic sphere are in constant search of them and their impacts. Some of the facts presented by de Waal (based on Booz Allen Hamilton survey among 1,200 large companies) indicate that majority of them are internal:

- from the 360 worst performers 87 percent of the value destroyed was caused by strategic missteps and operational ineffectiveness

- More than 50 percent of managers take decisions based on their gut feeling not on hard facts, and 36 percent has black boxes in the organisation of which they know hardly anything

- four out of every ten organizations do not actively work on increasing employee loyalty 
- Return rates and warranty costs are dramatically rising while at the same time customer satisfaction levels are steadily decreasing, a strong indication of the deteriorating quality of products

- The majority of companies which get into a crisis find themselves in this situation because of internal factors, of which dysfunctional management (48 percent of the cases) and inadequate management information systems (42 percent) are the most common causes [1]

As a matter of fact, despite strategies, tools and processes, individual biases persist in every organizations [2]. To increase the chance that an organisation is successful (or at least survives) in a long run - the focus has to be on internal processes and management of a company. Yet, are we able to measure the quality and maturity of an organisation's managerial ability?

Many researchers and business community members focus on the field of company performance's measurement. There are also important criticisms of PMS. Hamel [3] criticises the suitability of performance measurement theories and practices for modern organisations. Suggesting that the measurement and management of performance in organisations increases fear, reduces trust, promotes "command and control" systems, diminishing employee engagement. Thought it may seem a bit too strict, a recognition of a democratic, open, participative and fear-free management is being essential for the twenty-first century organisation. However, the interplay among performance measurement, performance management, employee engagement and performance remains poorly understood. Understanding this interplay is now considered critical for further development of the performance measurement theory [4, p. 1207].

Collins [5] proposes to identify a sole key performance indicator (e.g. sales per customer visit) as one of key drivers to outperform competition. On the opposite, Kaplan \& Norton [6] compare managing an organisation to the piloting an airplane, arguing that it is impossible to focus on one sole indicator (e. g. ground speed) ignoring the others (altitude, fuel level, engine temperature...). Neely et al. [7] pinpoints the enormous efforts spent on controlling (according to the Hackett Group an average corporation with turnover over $1 \mathrm{bln}$. USD spends 25000 man-days by planning and budgeting, Ford alone spends for the same $1.2 \mathrm{bln}$. USD yearly). Still there is very rare to find a person responsible for a quality and improvement of planning, budgeting and performance measurement. We can observe that no consensus can be given to answer the questions like: Are we measuring the right things? Do we measure enough/not too excessive? Is the cause-effect description in place?

An effort to overcame the gap and improve organisation's PMS offers Van Aken et al., by developing a tool assessing PMS [8]. However, no widespread usage can be recorded. In nonfinancial indicators seems the situation even worse - thought their importance is generally acknowledged by [9-11] and many others, a set of criteria or a tool, which provides lean and easy evaluation is missing. Hálek [9, p. 9-10] states that "In a global environment, where a major part of a business operates in an international environment, financial indicators seem insufficient, because for the most part they are historical indicators and do not reflect future developments". Therefore, the focus on performance models and management techniques grows. An attempt to find a tool evaluating non-financial criteria in a measurable and comparable way was conducted by the author. The only performance models fulfilling the need for comparable results are EFQM and Baldrige award criteria. Yet there is a serious obstacle for broader usage of them - the usage of these tools is complicated and especially small and medium organizations do not have enough resources for it [11]. Its deployment requires to undertake a multiday training and hiring an external assessor. The assessment itself takes several days, which represents an effort that SMEs are usually not willing to invest. Model is also primarily intended for improving operational management [1], not as a benchmarking tool. Moreover, as identified by Rusev \& Salonitis, [12, p. 277] “...the existing 
assessment tools are generally either biased towards process improvement or towards results. Assessment tools developed by Institutes that award prizes such as the MBQA and EFQM are results driven with little focus on culture and process efficiency". This might change with an introduction of new EFQM Model 2020 version.

As no suitable tool exists, a new model serving mentioned purposes was developed. It serves the management/owners of a company to better understand their company and to identify its strong/weak sides. It enables them to compare the results over a certain time period or compare with other organizations. This paper deals with practical usability and results of the model.

The CAT model was created by author of this paper to give both researchers and practitioners an easy-to-use tool, which enables them to assess organisational maturity using "soft" factors of an organisation like leadership and culture. It was tested on 12 independent organisations, the extent should be considered adequate [13]. It consists of 17 criteria grouped in three categories - Maturity, Stakeholders \& Others. They are: for Management - Leadership, Corporate culture, Quality, Performance, Controlling, Processes, for Stakeholders Communication, People, Employee selection process, Customers, Suppliers, Owners, Public authorities and for Resources - Financials, Exclusivity, Technology, External factors. The scaling of criteria is in a range from 1 to 5 with 0.5 step. Each functional category has its subtotal to better identify strong/weak sides of an organization Total achievable score is 17 - 85, where upper quartile score - above 68 points indicates well managed, mature organization, lower quartile (under 34 ) on the other hand, poorly managed entity likely to fail in a near future. The results are visualized for every respondent (and an average result) on a web chart indicating strengths and weaknesses. The results are scalable, comparable over time and enable benchmarking.

The usage of the model is based on a set of structured interviews with three respondents from an organisation. It shall include a top manager or owner; in case he is managing actively. Second respondent shall be another high-level manager, who has best overview of processes and daily business. Preferably executive director, financial director or similar. Third respondent shall be an opinion maker, a person, who is close to the front-line employees, but has a good overview over the organisation. This can be HR manager, head of trade unions, compliance officer, ombudsman or alike. Each participant is interviewed separately.

Both graphical output and text results and recommendation is provided by the tool.

\section{A practical usage of a model}

\subsection{A target company description}

As the results are rather sensitive, it was decided not to disclose the name of a target company. It was founded in 1991 in Czech Republic, is fully privately owned and is a manufacturing company. It employs approximately 180 people and yearly turnover is around 16 mil. EUR. Let's refer to it as a COMPANY.

\subsection{COMPANY analysis using CAT model}

According to the CAT model methodology was the assessment conducted with three company representatives. Firstly, the representative of employees was questioned, it was a head of Human resources department, acronym VH will be used for him. As a second interviewed was an executive director (LK), lastly both company owners (S+S) The strong/weak sides of a COMPANY were identified and areas requiring immediate attention were discovered. 


\subsection{Graphical results of an evaluation}

On Figure 1 there are the results of evaluation clearly visible on a web chart. All participants and their average are shown on the figure. It was expected, based on previous experience that high-level management (owners) ranking is higher than those of middle management. In this case the opposite was true, in most of the criteria the favourable answers were given by HR manager (VH), reflecting also opinions of the employees. The biggest difference can be seen at criterion Employee selection, where the HR manager was satisfied (with own work) at maximum level, whereas the owners received it as absolutely unsatisfactory. Together with criterion Performance were these two results most divergent, what suggests low amount of communication among owners and employees (when the owner is unsatisfied with respective departments performance, say for not fulfilling KPI's, it is necessary to implement some corrective actions and search for improvement). However, if the employees do not recognize the unsatisfaction, it is not reasonable to expect any improvement. Author's note: this resulted in parting of the COMPANY and both HR manager and executive manager.

Fig. 1: CAT model result for a COMPANY Source: own elaboration

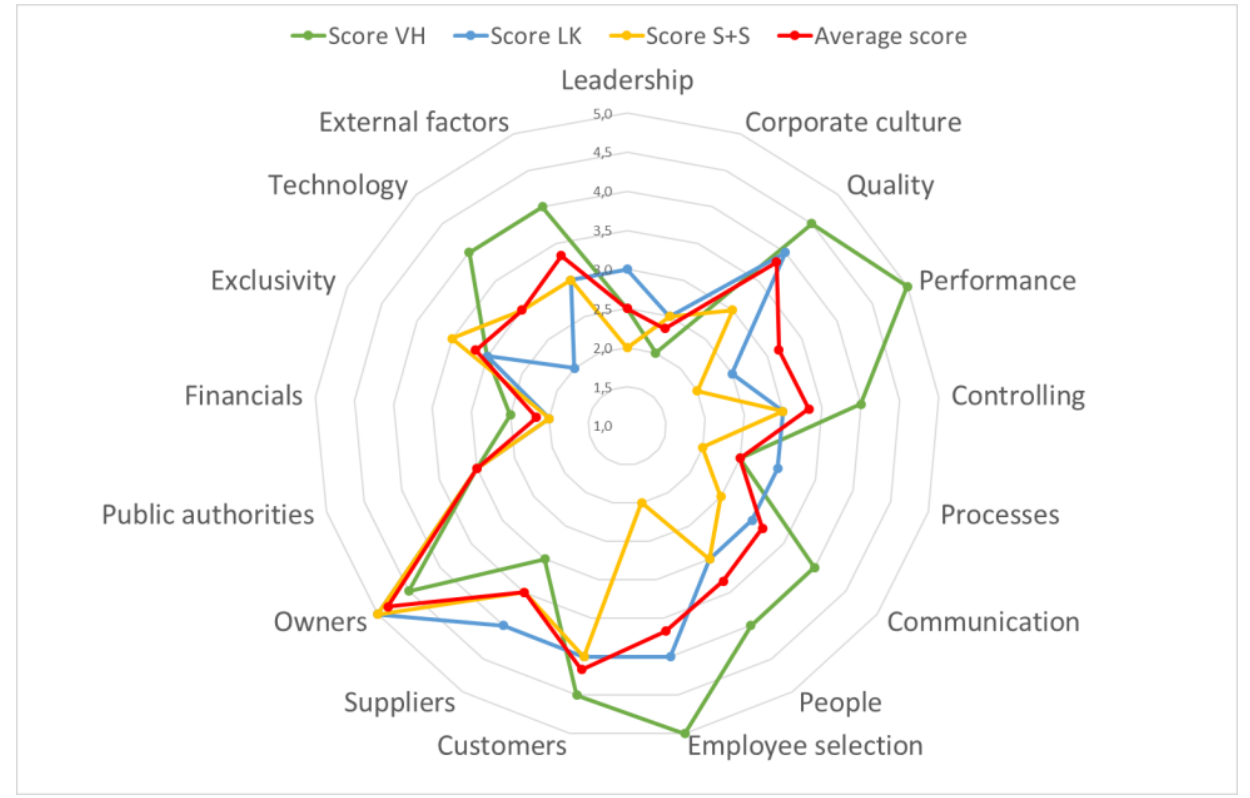

The main weaknesses can be seen in three criteria. First of them is Leadership, second is Corporate culture and third is Finance. For the last, it may be considered as a result than the root cause and you cannot trigger finance in a long run solely without improving in the criteria Leadership and Corporate Culture. This is also confirmed by Evaluation comments which the Model provides, see Chapter 2.4.

Results of Categories Maturity and Others were below average, an average result was achieved in Category Stakeholders, better result was not permitted by low score in criteria Communication, People and Public Authorities. 
Table 1. Assessment results in respective categories

\begin{tabular}{|c|c|c|c|c|c|c|}
\hline $\begin{array}{c}\text { Category } \\
\text { evaluation }\end{array}$ & Management & Limits & Stakeholders & Limits & Resources & Limits \\
\hline Maximum & & 30 & & 35 & & 20 \\
\hline $\begin{array}{l}\text { Upper } \\
\text { quartile }\end{array}$ & & 24 & & 28 & & 16 \\
\hline Average & & 18 & & 21 & & 12 \\
\hline $\begin{array}{l}\text { Lower } \\
\text { quartile }\end{array}$ & & 7,5 & & 9 & & 5 \\
\hline Minimum & & 6 & & 7 & & 4 \\
\hline Score: & 17,7 & & 25,7 & & 11,7 & \\
\hline
\end{tabular}

If we compare overall results of each interviewed, the lowest evaluation was achieved surprisingly by owners $(\mathrm{S}+\mathrm{S})$. All other results were above-average, in some criteria we can expect deeper knowledge of owners than HR manager, resulting in informed pessimistic view in comparison to the view of HR or executive manager.

Table 2. Assessment results of each participant

\begin{tabular}{|c|c|c|c|c|c|}
\hline $\begin{array}{l}\text { COMPANY } \\
\text { evaluation }\end{array}$ & $\begin{array}{l}\text { Average } \\
\text { score }\end{array}$ & Score VH & Score LK & Score S+S & Limits \\
\hline Maximum: & & & & & 85 \\
\hline Upper quartile & & & & & 68 \\
\hline Average & & & & & 51 \\
\hline Lower quartile & & & & & 34 \\
\hline Minimum: & & & & & 17 \\
\hline Score: & 55,0 & 62,0 & 54,0 & 49,0 & \\
\hline
\end{tabular}

\subsection{Overall evaluation comments}

Total achievable score is 55 , what is slightly above average (55 points). The average result indicates an organisation with fair level of management maturity.

The highest ranking was provided by $\mathrm{VH}, \mathrm{LK}$ was on average, $\mathrm{S}+\mathrm{S}$ were below the average.

The best results achieved category Stakeholders, from criteria both Customer and Owners. Categories Management and Others scored below-average.

Significantly below average are the criteria Leadership, Corporate Culture, Processes and consequently Finance. 
- A remarkable difference was identified in criteria Performance and Employee Selection.

- The company excels in focus on its customers and quality

- The downsize is in setting and living its vision, values and objectives into operations, relation of its strategy to targets and performance evaluation

- Exceptional relations with stakeholders, beside owners also customers

- Overall result is average, the recommendation is except running improvement projects to focus more on soft factors of an organisation, on sharing common values, to motivate on joint success (ownership culture). To focus more on internal communication among departments.

- It is recommended to formalize management processes (minutes of meetings, tasks setting and evaluation, managing of managers instead of front-line employees.

\subsection{Evaluation results and next steps}

The analysis discovered a weakness in internal communication and managing style as itself. Consequently (this is author deduction only) non-fulfilling of financial targets in last two years with worsening trend. The strategical meeting on mid-level management was organised by the executive manager to identify quick wins and to implement mid- and long-term measures.

Just half of the measures were not of financial or technological nature but dealt with issues like communication, motivation or organisation. This confirms the findings from CAT model that main problem within the organisation is communication, management style and company culture.

The organisation did not fully utilize the innovation potential of its employees (no improvement process was established, the employees did not come with own proposals), no coherent system of internal projects and changes management existed. It caused ineffective resources utilisation, duplicability, moderate progress and projects delays resulting in overall low motivation. The process did not meet expectations and did even not earn sufficient management.

Measures implemented by the company owners were among others much closer attention on company performance and processes, personal changes, profitability analysis on customer level and cost optimisation. This lead quickly to improvement in economic results see monthly Gross profit development as most important of them in figure 3. Even though seasonal effect in summer months the improvement can be identified, confirmed also by trend line.

However, little was done in regards of communication, company culture. Managers tried to focus on their leadership style, the future development and future assessment will confirm, if the changes were sufficient and the improvement did not exposit a small adjustment only. 
Fig. 2 Development of Gross Profit with improvement since summer 2019. Source - own calculation on COMPANY data.

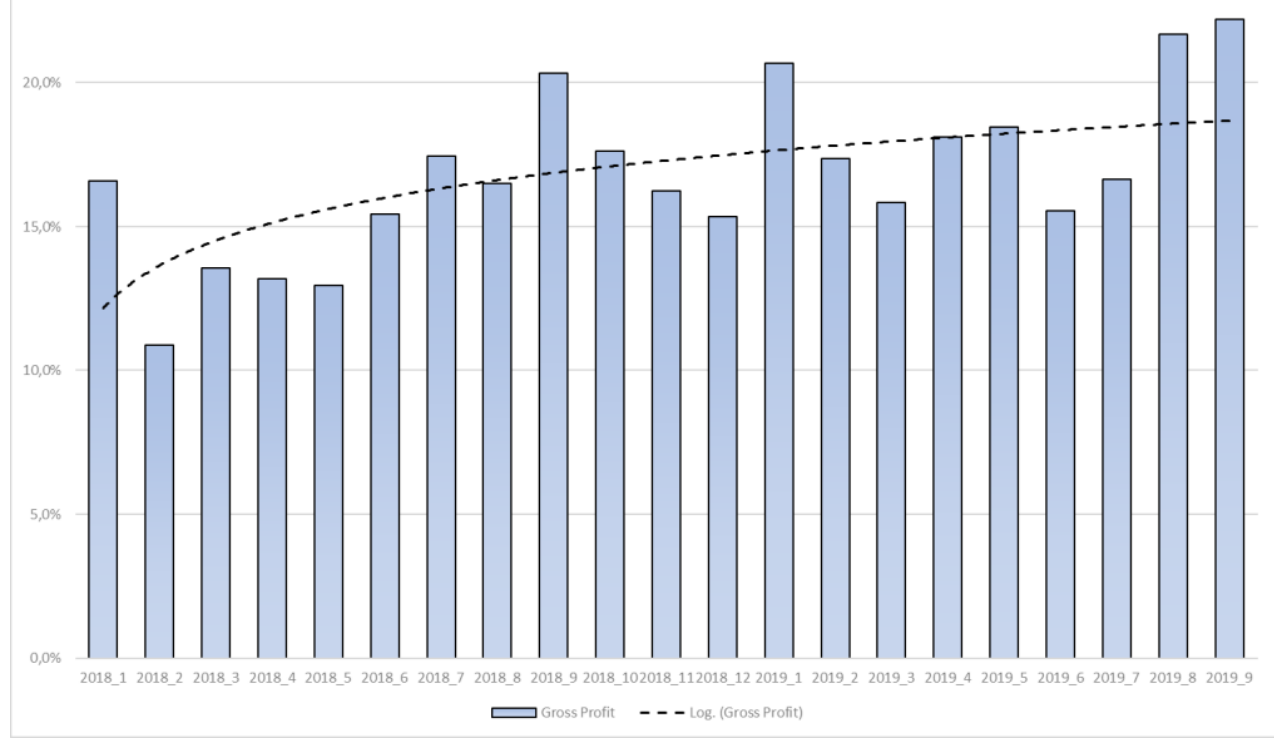

\section{Conclusion, further application}

The CAT model was used in order to help COMPANY when it faced deterioration of their market position and consequently worsening their financial results. It identified as most important findings:

- for several areas, there is a significant distortion in perception of company owners and their management, resulting in personal changes on positions of executive manager and HR manager

- the COMPANY is poor in maintaining its company culture, internal communication and leadership style. Presumably the financial problems can be attributed to these flaws

- $\quad$ excellent results were achieved in criteria Customers and Owners and also Quality

After the assessment the performance of COMPANY improved. There has been, beside personal changes, increased attention paid by the owners and many corrective actions were taken. As no significant change occurred in order to improve leadership style and internal communication, the long-lasting effect of these measures can be questioned. The new executive manager and his leadership style will be decisive in forming the COMPANY success in next years.

The usage of CAT model proved to be helpful in identifying weaknesses of an assessed organisation and proposing further actions. However, it still delivers identified weaknesses and recommendations to rectify only, the actions and measures have to be taken and implemented by executive management.

It would be reasonable to conduct the same assessment in 1-2 years period to track possible changes and evaluate effect of measures taken. Also, it would be helpful to conduct more assessments in similar organisations to allow benchmark for a COMPANY. 


\section{References}

1. Waal, A.a. De. "The Characteristics of a High Performance Organisation." SSRN Electronic Journal, (2006). Doi:10.2139/ssrn.931873.

2. Powell, T. C., Lovallo, D. and Fox, C. R. Behavioral strategy. Strategic Management Journal, (2011). 32. doi:10.1002/smj.968

3. Hamel, G. (2009), "Moon shots for management”, Harvard Business Review, Vol. 87 No. 2, pp. 91-98.

4. Smith, M. and Bititci, U.S. (2017), "Interplay between performance measurement and management, employee engagement and performance", International Journal of Operations and Production Management, Vol. 37 No. 9, pp. 1207-1228

5. Collins, J. C. Good to Great: Why Some Companies Make the Leap... and Others Don't, USA: William Collins, 2001

6. Kaplan, R. S., \& Norton, D. P. Linking the Balanced Scorecard to Strategy. California Management Review. 39/1 (1996)

7. Neely, A. D., Adams, C., \& Kennerley, M. The performance prism: The scorecard for measuring and managing business success. (Prentice Hall Financial Times 2002)

8. Van Aken, E., Letens, G., Farris, J.A., Coleman, G.D., \& Van Goubergen, D. Application of an integrated tool for assessing performance measurement system effectiveness and maturity. International Journal of Productivity and Performance Management. 54/5-6 (2005)

9. Hálek, V. Non-financial indicators in the valuation process. (Sciemcee Publishing, 2016)

10. Ittner C.D. \& Larcker, D. F. Coming Up Short on Nonfinancial Performance Measurement. Harvard Business Review, (November 2003)

11. Aschenbrennerova, $H$. Měřením a řízením výkonnosti ke zvyšování konkurenceschopnosti malých a středních průmyslových podniků v období globální finanční krize. Journal Úspěch. 10, 1 (2010)

12. Rusev, S. J., Salonitis, K. Operational Excellence Assessment Framework for Manufacturing Companies. Procedia CIRP. 55, 5th CIRP Global Web Conference Research and Innovation for Future Production (CIRPe 2016). ISSN: 2212-8271.

13. Long, T.B., Blok, V., Dorrestijn, S. \& Macnaghten, P. The design and testing of a tool for developing responsible innovation in start-up enterprises, Journal of Responsible Innovation, 7/1, 45-75 (2020)

\section{Enclosures}


Enclosure 1: The results of the assessment and full CAT model:

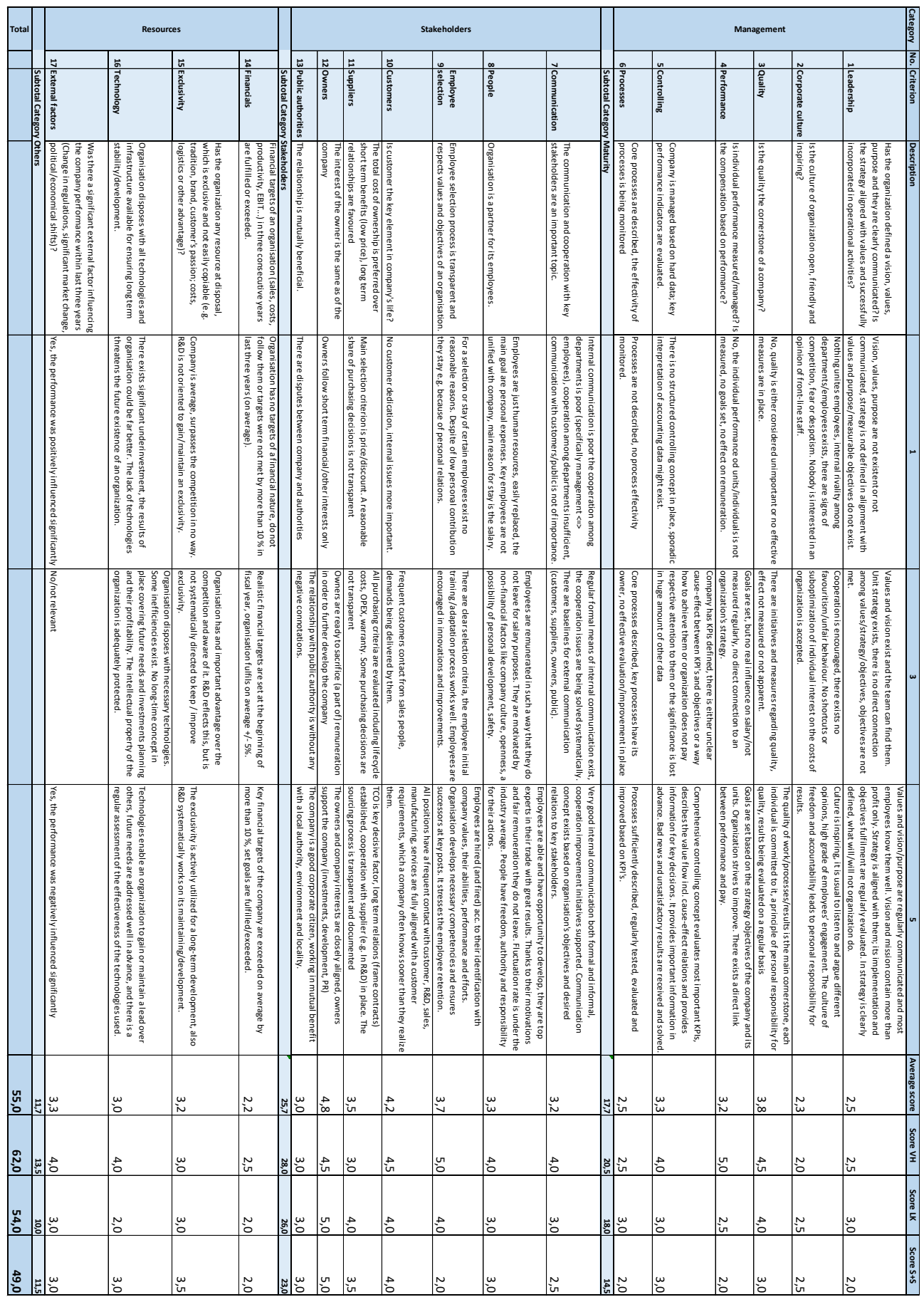

